\title{
A RETÓRICA DO MÉTODO (TUCÍDIDES I.22 E II.35)
}

\author{
Francisco Murari Pires \\ Depto. de História, FFLCH da USP
}

RESUMO: Propõe-se, no presente artigo, entender o "silenciamento metodológico" tucidideano constatado ao longo de sua narrativa reconstituidora dos acontecimentos da Guerra do Peloponeso face à proclamação de princípios firmada em seu Proêmio (I.22), como recurso de argumentação retórica a projetar a fama da excelência historiográfica de seu autor. Para tanto faz-se uma aproximação analítica desse Proêmio com o similar Proêmio do célebre Discuros Fúnebre de Péricles em honra dos guerreiros mortos no primeiro ano de guerra (II.35).

ABSTRACT: Through a comparative analysis of the so called "methodological" chapter (I.22) of the Proem of the thucydidean History with the Proem of the famous Funeral Oration of Pericles (II.35) in honour of the athenians dead in the first year of the war, this article envisages to understand the purposes of that chapter rather as a rhetorical device that projects the excellence of the historiographical art of his author than as a positive proposition of "methodological" rules of facts' reconstitution.

PALAVRAS-CHAVE: Tucídides, Historiografia, Metodologia, Retórica, Péricles

KEYWORDS: Thucydides, Historiography, Metodology, Rhetoric, Pericles

Ao encerrar, no Proêmio de sua obra histórica, aquelas declarações de principios narrativos que nós modernos entendemos tradicionalmente por "metodológicas" " Tucídides tece uma reflexão final de al-

\footnotetext{
${ }^{1}$ A abordagem mais sistemática dos princípios da narrativa onomasiológico (a questão do sujeito), axiológico (a questão da grandeza), metodológico (a questão da verdade), teleológico (a
}

cance um tanto intrigante. Como já o fizera logo antes, no tocante à reconstituição dos discursos pronuncia-

questão da utilidade), arqueológico (a questão do início) e etiológico (a questão da causa) -, que as histórias herodotena e tucidideana ambivalentemente herdam da epopéia homérica, tanto os desdobrando quanto deslocando em sua obras, encontra-se em MURARI PIRES (1995, p.6-20). 
dos durante a guerra, também para as ações praticadas o historiador firmou a autópsia ${ }^{2}$ como princípio de derivação, e pois fundamentação, informativa de sua história. Ora, mas justamente o fato da presença aos acontecimentos assim imposta como condição informativa de seu relato implicou um impasse para a devida reconstituição dos mesmos pelo historiador, pois:

os que estiveram presentes a cada um dos acontecimentos não diziam as mesmas coisas acerca dos mesmos fatos, mas sim conforme fosse ou a sua inclinação por um dos lados, ou a sua memória. (A Guerra dos Peloponésios e Atenienses, I.22.3)

O historiador acusa aqui, como aporia informativa básica para a sua narração dos acontecimentos bélicos, o dilema posto pela diversidade discordante de relatos entretanto concernentes a uma unicidade factual: sobre os mesmos fatos, distintos observadores dão informes divergentes ${ }^{3}$.

O impasse maior assim detetado é propriamente inerente às determinações da situação mesma de presença cognitiva à ocorrência dos acontecimentos. Pois, as pessoas que presenciaram os acontecimentos, os presenciaram porque participavam de suas ações. E eram partícipes porque engajados por algum dos lados diversamente envolvidos nas disputas do conflito beligerante. Então, ao ensejo determinante dessa sua participação, viram os fatos (pre)dispostos por suas inclinações pessoais e, assim, consoante à ótica contaminada de seu engajamento. De modo que sua percepção dos fatos, e seu condizente relato, compromete-se por essa parcialidade de seu olhar, não apenas e tanto porque se tratem de subjetividades diversas, mas, sobretudo, porque, devido a engaja-

\footnotetext{
${ }^{2}$ Para a problemática da autópsia como princípio de fundamentação informativa da historiografia grega, vejam-se o artigo de Nenci e, mais recentemente, a obra de Schepens, ambos citados na bibliografia.

${ }^{3}$ Veja-se PARRY, 1988, p.103.
}

mentos antagônicos, respeitam a enfoques inerentemente conflitantes de constatação informativa dos acontecimentos presenciados.

E, todavia, assim advertidos, nós leitores, de tais aporias e impasses, constatamos - um tanto perplexos, algo decepcionados, ou por vezes mesmo incrédulos senão desconfiados ${ }^{4}$ - que pouco, se quantificado pelo total da obra, dessa dialética dos informes factuais comparece expressamente inscrito na narrativa tucidideana dos eventos bélicos, não mais que uma dezena de passagens.

Assim, por duas vezes Tucídides adverte a existência de relatos conflitantes dos acontecimentos então narrados.

Há o registro (Ibid., II.5) da dicotomia de versões - dos tebanos, de um lado, e dos platenses, de outro - quanto aos termos que uns e outros alegavam ter acertado entre si para a soltura dos guerreiros aprisionados pelos últimos - entretanto por eles no fim massacrados -, com aqueles acusando a transgressão do juramento comprometido pelos platenses, contra estes negando terminantemente que tivessem prometido libertá-los de imediato e mesmo que o tivessem formalmente prestado.

Há o apontamento (Ibid., VIII.87) da dificuldade de conhecer-se o verdadeiro motivo do deslocamento de Tissafernes a Aspendo face aos comprometimentos bélicos de sua aliança com os lacedemônios: supostamente lá ele reuniria a frota fenícia para utilizá-la compondo o esforço de guerra espartano, propósito, todavia, assim não consumado naquela ocasião! Por um lado, conheciam-se as razões declarativas atribuídas ao próprio Tissafernes, mas, de outro, denunciava-se a falsidade das mesmas segundo algumas versões que especulavam diversamente seus reais intuitos.

\footnotetext{
${ }^{4}$ Confiram-se: WESTLAKE, 1977, p.34; WOODMAN, 1988 , p.16; HORNBLOWER, 1987, p.22; COGAN, 1981, p.xii-xiii.
} 
Mais algumas outras vezes Tucídides declara não poder precisar a plena reconstituição do acontecimento narrado, ou porque provido apenas por dados suspeitos ou mesmo porque deles carente.

Há a admissão (Ibid, V.68) do desconhecimento dos montantes numéricos exatos dos contingentes que se enfrentaram na batalha de Mantinéia, falha informativa aqui devida a que, por um lado, os próprios lacedemônios ocultavam os seus, justamente porque antes obnubilavam os segredos de suas realidades institucionais; já, de outro, ocorria o inverso, por dados fornecidos suspeitos, com a gabolice dos homens exagerando as coisas que lhes diziam respeito. Conseqüentemente, Tucídides (Ibid V.74) aponta ainda a dificuldade de verdadeiramente precisar o número de espartanos mortos naquele combate, atendo-se, pois, ao montante de baixas de que então se falava.

Há a censura crítica tucidideana (Ibid, III.113) que recusou informar o número de ambraciotas mortos na campanha de Anfilóquia, assim afastando de sua obra tais suspeitas de relato inverídico, pois era totalmente inacreditável o montante que lhe fora apresentado, se avaliado contra a população total da cidade.

Há a alegação tucidideana (Ibid, VII.44) da dificuldade de discernir as vicissitudes do assalto desastroso cometido pelos atenienses contra as fortificações siracusanas das Epípolas, nem as tropas agressoras nem as defensoras podendo relatá-las com clareza justamente porque turvada sua visão pelas trevas noturnas do combate.

Há a confissão tucidideana (Ibid, VI.60) da ignorância generalizada quanto aos verdadeiros culpados da mutilação dos Hermas de Atenas às vésperas da expedição siracusana, pois, pelo processo mesmo que ajuizara o caso não se pudera ter certeza de que as revelações então obtidas pelas denúncias de um dos próprios acusados fossem verídicas ou, pelo contrário, falsas.

Há a observação tucidideana (Ibid, VII.87) da dificuldade de precisar o total de atenienses que caiu prisioneiro em Siracusa, o historiador podendo apenas afirmar que não fora inferior a sete mil.

E há a constatação tucidideana (Ibid, III.87) do desconhecimento do número de atenienses - que não hoplitas ou cavaleiros - abatidos pelo recrudescimento do surto de peste na cidade no terceiro ano da guerra.

Diversamente de Heródoto ${ }^{5}$, a narrativa historiográfica tucidideana não faz aflorar a dialética de suas fontes informativas, e tampouco revela os procedimentos de sua metodologia crítica porque derivou a reconstituição dos fatos consagrados na redação de sua história. ${ }^{6}$ "Na narração propriamente dita", observa Butti de Lima (1996, p. 96), "o historiador, enquanto historiador, está ausente", e nela deparamos antes "a apresentação direta dos fatos". O discurso narrativo tucidideano é predominantemente, senão avassaladoramente, composto por impressões de apenas resultados factuais, quaisquer que sejam as identificações dos informantes e quaisquer que sejam as operações analíticas de uma sua suposta crítica averiguadora de veracidade. ${ }^{7}$

5 “....ao passo que Heródoto associa freqüentemente o leitor a suas investigações, lhe desvenda as origens e lhe dá a conhecer suas próprias reflexões e arrazoados, Tucídides limita-se manifestamente a descrever de uma vez por todas seu método histórico-crítico, e a expor, para o restante, o resultado de suas pesquisas" (SCHEPENS, 1980, p.96).

${ }^{6}$ Razão porque, mais recentemente, as projeções da crítica moderna de reconhecimento de sua identidade historiográfica nos historiadores antigos andaram saudando a "melhor cientificidade metodológica" herodotena, em prejuízo da mais afamada tucidideana, veleidade esta de ajuizamento, entretanto, não imune a certos percalços, pois, nem sempre "os princípios que levaram Heródoto a indicar suas fontes correspondem certamente àqueles que hoje se definem como científicos" (BUTTI de LIMA, 1996, p.102).

7 "A fórmula sucinta do diz-se que (légetai) basta para transpor a narração do nível dos fatos ao da história" (BUTTI de LIMA, 1996. p.96). "Mas, quando a história se torna pesquisa da verdade, o narrador não tem outra coisa a fazer que retrirar-se ... Ele é este narrador ausente, que deixa falar os fatos: objetivo" (HARTOG, 1982, p.26). 
Perpassa, assim, pela obra um certo silêncio metodológico operado por um ocultamento do historiador $^{8}$, o qual, antes do que integrar a dialética de sua heurística, a oblitera, e antes do que expor quais sejam as determinadas regras e preceitos de sua crítica, dá esta apenas por pressuposta e realizada. Pois, tudo o que Tucídides revela nesse sentido reduz-se à mínima declaração programática de seu dito capítulo "metodológico": na reconstitução dos acontecimentos o historiador almejou sempre alcançar a precisão, acribia .

Diante de uma tal idiossincrasia de silêncio metodológico, podemos - nós, crítica moderna -, envidar a (re)descoberta dessa metodologia tucidideana não bem revelada, e entretanto consumada por sua obra historiográfica, assim melhor identificando por quais regras e preceitos, ou que demais critérios, de crítica de veracidade Tucídides analiticamente operou o ajuizamento dos relatos informativos então coletados de modo a superar os impasses que, para tanto, haviam sido pelo historiador expressamente denunciados. ${ }^{10}$

Podemos ainda imaginar o historiador Tucídides a zelosa e persistentemente colher mesmo os relatos divergentes, de ambos os lados, para confrontá-los visando a alcançar sua veracidade factual unitária. ${ }^{11}$ Podemos ainda projetar que também para a reconstituição dos acontecimentos do tempo presente da Guerra do Peloponeso, Tucídides fez valer os mesmos preceitos de crítica factual já antes por ele mesmo reclamados para o exame das tradições antigas, dos

\footnotetext{
${ }^{8}$ ORWIN (1994, p. 5) lembra, em epígrafe à sua obra, o elogio que Rousseau dirige a Tucídides no Emílio: Longe de interpor-se entre os acontecimentos e seus leitores, ele se oculta. O leitor não mais acredita que lê; ele acredita que vê.

${ }^{9}$ Para a questão do entendimento da concepção tucidideana de acribia como precisão veja-se, por último, CRANE, 1996, p.50-65.

${ }^{10}$ Nesse sentido veja-se, por último e sempre apuradamente equilibrado em suas apreciações críticas, o estudo de BUTTI de LIMA - L'Inchiesta e la Prova, 1996.

${ }^{11}$ Confira-se PROCTOR, 1980, p. 16.
}

tempos passados. ${ }^{12}$ E podemos ainda especular operações detalhadas de verdadeiras checagens informativas dos relatos, ponto por ponto, testando-os através das mais variadas ordens de realidades englobadas pelo conhecimento tucididiano. ${ }^{13}$

Nos fluxos e refluxos desses estudos, mais ou menos diversamente tendo por pano de fundo as vicissitudes das projeções modernas de identificação da obra discursiva tucidideana bipolarizada pela contraposição de categorias "ciência" versus "arte" 14 , delineia-se, mais recentemente, uma certa tendência interpretativa que envida ressaltar no "silêncio metodológico" tucidideano respeitante à reconstituição dos acontecimentos bélicos a eficácia de uma retórica da objetividade. ${ }^{15}$

Todavia, Tucídides mesmo, em seu texto, revela apenas e tão somente, não as soluções por ele precipuamente alcançadas, mas antes as dificuldades por ele "metodologicamente" advertidas. Como as superou, por quais eventuais procedimentos e operações analíticas, Tucídides não diz. Aqui, mais do que tudo, imperam os silêncios do estilo elíptico tucidideano.

Não haveria, então, ainda lugar para interrogarmos também justamente outras razões desse silêncio, e inquirir por algum seu sentido na trama mesma do discurso "metodológico" tucidideano? Pois, tal silêncio e elisão não é tanto algo a ser estranhado, pelo contrário, eles condizem mesmo com a intriga tecida

\footnotetext{
${ }^{12}$ Confiram-se: CONNOR, 1984, p.27-28; PLANT, 1988, p.202; LORAUX, 1984, p.148 e 152; EDMUNDS, 1975, p.156; BUTTI de LIMA, 1996 p.116 e p.127-170 (especialmente, p.148-151) ${ }^{13}$ Confiram-se: CONNOR, 1984, p.27-28; COGAN, 1981, p.xii-xiii. ${ }^{14}$ Vejam-se os apontamentos gerais dados por CONNOR, 1984, p.4-6, mais DOVER, 1983, e também por ORWIN, 1994, p.7-8. ${ }^{15}$ Vejam-se, por exemplo: HARTOG, 1982, p.26; LORAUX, 1984; WOODMAN, 1988, p.23; CRANE, 1996, p.27-29; BUTTI de LIMA, 1996, p.97-98 e 126. Tendência, entretanto, que suscita já algumas advertências críticas: BUTTI de LIMA, 1996, p.116s e 126-128; DESIDERI, 1996, p.973-974.
} 
pela própria arquitetura retórica de formulação de pensamento dessa sua reflexão metodológica, toda ela comandada por uma ordenação de natureza quiástica, plena de figuras de antíteses e de reversões assertivas. ${ }^{16}$

Pois, inicialmente, quando tratava da reconstituição dos discursos, Tucídides principiou suas considerações declarando quais eram as dificuldades, justamente postas por um reclamo de acribia, dificuldades estas de tal monta que inviabilizaram o procedimento narrativo de simples reprodução dos relatos recolhidos junto aos informantes. Então, postas tais dificuldades, o historiador contornou esse primeiro impasse firmando que ele mesmo, nominalmente, apreenderia, por seu parecer, a realidade dos discursos, fundando-a a partir da gnóme efetivada por cada um e pautando-se pela acribia possível de aproximação do que fora realmente dito. Depois, passando agora à questão da reconstituição das ações, ou seja, dessa categoria de acontecimentos contrapositiva aos discursos, Tucídides reverteu os procedimentos ad otados. Agora, ao revés do que fez para os discursos, dispensou seu ato nominal de emissão de um parecer pessoal enquanto sujeito da narrativa, preferindo, ao invés, acolher os relatos dos informantes, justamente dispensados no caso dos discursos. E, assim bem os acolhendo, lembrou novamente, como para os discursos, que também sobre eles imperava o reclamo da acribia. Daí, terminou por declarar quais eram então as dificuldades. ${ }^{17}$ Em síntese, para os discursos aludiu às dificuldades para apresentar as soluções; já para as ações, aludiu às soluções para bem realçar, pelo contrário, as dificuldades.

${ }^{16}$ Entre outros, vejam-se os estudos de HAMMOMD, 1952; ELLIS, 1991; WOODMAN, 1988; ALMEIDA PRADO, 1972; e MURARI PIRES, 1995.

${ }^{17}$ Já Woodman chamou a atenção para este ponto: "Observe-se que a ênfase é totalmente colocada sobre a dificuldade do processo antes do que sobre os resultados alcançados" (1988, p. 16).
Ora, mas uma análoga intriga retórica tramada pela obra narrativa tucidideana encontra-se também no Proêmio do célebre Discurso Fúnebre atribuído a Péricles. ${ }^{18}$ Nesse seu pronunciamento de abertura, o discurso marca, em relação à própria prática institucional da Oração Fúnebre em honra dos guerreiros que tombaram pela cidade, uma reivindicação de originalidade crítica ${ }^{19}$. Assim, ele começa contestando e, pois, por princípio divergindo, frontalmente do que se declara ser a praxe de iniciar a Oração Fúnebre tecendo louvores ao legislador que instituiu tal prática:

A maioria dos oradores que me precedeu neste lugar louva aquele que introduziu esta alocução no cerimonial de costume, considerando como belo que, no momento de seu enterro, as vítimas da guerra sejam assim celebradas. De meu lado, estimaria suficiente que, para homens cujo valor traduziu-se em atos, fossem prestadas homenagens igualmente por atos, como vedes que se faz hoje nas medidas oficiais aqui tomadas para seu sepultamento. Os méritos de todo um grupo não dependeriam de um único indivíduo, cujo talento maior ou menor lhes coloca em causa o crédito. Pois que é difícil adotar um tom justo, num assunto em que a simples apreciação da verdade encontra penosamente bases seguras: bem informado e bem disposto, o ouvinte pode muito bem julgar a exposição inferior ao que ele deseja ou sabe; mal informado, pode, por inveja, estimá-lo exagerado, quando aquilo que ele ouve ultrapassa suas próprias capacidades; pois não se tolera ilimitadamente elogios pronunciados a respeito de um terceiro, cada um o fazendo na medida em que se acredita capaz de realizar, ele mesmo, os feitos que ouve relatar; além disto, com a inveja, nasce a incredulidade. ${ }^{20}$

O discurso inaugura-se, pois, contestando por princípio a praxe que, pelo louvor que ela presta ao

\footnotetext{
${ }^{18}$ Entre outros, vejam-se os comentários de GAISER, 1975, p.2427; PARRY, 1981, p.160 e, especialmente, de LORAUX, 1981, p.232-241.

${ }^{19}$ Já destacado por ORWIN, 1994, p.16.

${ }^{20}$ II.35.1-2. A partir da tradução francesa de JACQUELINE de ROMILLY, 1962, p.26.
} 
instituidor da oração fúnebre, aceita inquestionadamente a propriedade da mesma. Ele, pelo contrário, assinala sua singularidade denunciando-a duplamente. Antes de mais nada, a instituição é não só desnecessária quanto equivocada. Desnecessária, porque bastam os próprios atos constituintes do cerimonial de sepultamento para manifestar o reconhecimento do valor das ações e feitos dos guerreiros mortos. E equivocada porque, ao colocar esse reconhecimento do valor guerreiro consumado em atos na dependência do talento retórico do orador que os celebra, corre-se o risco de, paradoxalmente, não se reconhecer tal valor, mas sim colocá-lo sob suspeição.

E, mais ainda, a instituição é totalmente inadequada por si mesma, dada a aporia insolúvel própria do empreendimento que ela, todavia, se propõe, pois que a arte da fala, a techné discursiva, não comporta habilidade suficiente para superá-la: qual o tom justo a ser empregue enquanto elogio, de forma que este elogio seja apreciado como a adequada manifestação discursiva de reconhecimento daquele valor consumado em feitos? Como encontrar a medida de elogio que responde com justeza pelo valor dos feitos cumpridos? Ora, descortina-se um horizonte de possibilidades alternativas para o orador que são antes impossibilidades, pois que o coloca num impasse, dado que ele fica inelutavelmente condenado a desagradar seus ouvintes: ou se acusa a insuficiência do elogio, quando este desgosta aqueles que, justamente conhecedores dos feitos guerreiros realizados, dispõem-se e esperam que o discurso não inferiorize seu valor; ou, pelo contrário, se acusa o exagero do elogio, quando este desgosta aqueles que, exatamente por desconhecerem os feitos, medem a plausibilidade destes segundo e por sua própria (in)capacidade de realizá-los. De modo que, neste caso, por inveja, estimam exagerada a apreciação que refere feitos que os ultrapassam, astuciosamente escamoteando na verdade os seus limites pessoais. E o resultado, então, é que sempre o orador será desacreditado por seu público, quer acu- sado de errar por falta quer, pelo contrário, por excesso laudatório. ${ }^{21}$

E, assim, a apresentação do Discurso Fúnebre pericleano principia totalmente desqualificando a prática mesma de modalidade discursiva em que ele, entretanto, se integra. E de forma aparentemente radical, pois que denuncia qual é a sua inconsistência intrínseca: a apreciação que descortina suas possibilidades alternativas a projeta antes como impossível! E, todavia, o Discurso Fúnebre de Péricles a desacredita, e, entretanto, paradoxalmente, logo a seguir, antes a enceta e cumpre, efetivando-a enquanto tal. Daí um seu preciso sentido e finalidade retórica embutido por este seu procedimento convencional de captatio benevolentiae $^{22}$ : se ele realiza o, todavia, impossível enquanto proposição discursiva, algo que não há fórmula retórica que viabilize, tanto melhor se pode apreciar a excelência e o mérito singularmente excepcional do orador que, assim mesmo e todavia, o realizou! E, para realizar essa modalidade discursiva de elogio, não há qualquer solução determinada, imperam apenas as impossibilidades postas pelas dificuldades, pelas aporias claramente afirmadas.

Ora, mas ocorre, com esta projeção tucidideana da excelência retórica pericleana consagrada por esse seu suposto desempenho ao iniciar-se a Guerra do Peloponeso, algo similar ao que se passa, no texto da

\footnotetext{
${ }^{21}$ Considere-se, paralelamente, a similar intriga retórica figurada pelo discurso de Otanes, no célebre Debate Persa herodoteano (III.80), ao denunciar a irracionalidade da inveja, e inconseqüência das calúnias, da figura do tirano nas relações com seus súditos, o qual nas cortesias moderadas que estes lhe dirigem acusa falta de adulação, mas nas adulações exageradas, vil bajulamento. ${ }^{22}$ Vejam-se as obras citadas logo acima de Gaiser e de Loraux; por outro lado, considerem-se as justas advertências ponderadas por HORNBLOWER, (1987, p.101s), acerca do alcance dos ajuizamentos que apontam para as relações entre a obra discursiva tucidideana e a sistematização teorizante da arte retórica.
} 
Odisséia, com os elogios firmadores da excelência no domínio das artes do canto e narração das gestas heróicas - quer aquele com que Odisseu distingue Demódoco, quer o outro em que é Alcino que antes assim honra o herói mesmo ${ }^{23}$ : os ecos de ambos alcançam e ressoam sua projeção valorativa na figura do sujeito poético que os memorizou, tradicionalmente representado pelo nome de Homero. Igualmente, o modo discursivo porque o historiador reconhece, e consagra na memória histórica, a perícia retórica de Péricles, proclama, pela sutil inteligência de um mesmo belo silênciamento de si mesmo, antes a sua própria, pessoal, arte retórica, deste sujeito historiante da guerra cujo nome chancela o texto desde sua abertura: Tucídides de Atenas!

E, não poderíamos ainda reconhecer homólogos procedimentos de arrazoado retórico nesse outro Proêmio discursivo da obra tucidideana, o qual insere no seu bojo a apreciação da suposta questão metodológica de reconstituição dos acontecimentos bélicos? Aqui também Tucídides aponta incontestáveis dificuldades de realização, porém não tendo por finalidade fundamentar uma argumentação de sua desistência e renúncia, pois que ele obra justamente o contrário, consumando, a seguir, a realização narrativa que, paradoxalmente, as supera. E as supera justamente aparentando apenas pressupor uma solução determinada, mesmo porque solução assim sugerida

\section{Bibliografia}

ALMEIDA PRADO, A. L. Tucídides. História da Guerra do Peloponeso I. São Paulo, FFLCH-USP, 1972, 214p.

BUTTI de LIMA, P. L'Inchiesta e la Prova. Immagine storiografica, pratica giuridica e retorica nella Grecia classica. Torino, Einaudi, 1996, 201p.

COGAN, M. The Human Thing. Chicago, The University of Chicago Press, 1981, 309p.

${ }^{23}$ Odisséia, VIII.486-498 e XI.363-376. como indeterminável. A finalidade retórica é apenas firmar as dificuldades, e não anunciar suas soluções. Assim, tanto mais se aprecia a capacidade historiográfica de quem, entretanto, transpõe, não regras metodológicas descobertas, mas sim, pela obra narrativa de fato consumada, os impasses então declarados, pois, das dificuldades e aporias, a Guerra dos Peloponésios e Atenienses não revela mais os traços, a não ser por algumas ínfimas alusões esparsas.

Examinada então esta problemática no âmbito da convencionalmente intitulada seção metodológica da obra tucididiana, dada sua intrínseca conformação retórica ordenadora, a questão dos procedimentos analíticos de objetivação dos relatos na reconstituição das ações praticadas na guerra, não tenha, nem seja para ter, solução, quer apenas não declarada, quer nem mesmo determinada, ou, quem sabe, sequer almejada.

Então, a suposta problemática dos vazios do "silêncio metodológico" tucidideano, considerado no âmbito mais precípuo de sua formulação no Proêmio (capítulo 22 do livro I), não poderia ser também apreciada pela solução que Aristóteles deu ao equívoco enigma da realidade histórica da Atlântida? Pois, pondera o filósofo, ocorre com a Atlântida o mesmo que com o muro de defesa edificado pelos gregos em Tróia: o poeta que o construiu foi também quem igualmente o destruiu, fazendo-o desaparecer para sempre da história.

CONNOR, W.R. Thucydides. Princeton, Princeton University Press, 1984, 265p .

CRANE, G. The Blinded Eye. Thucydides and the New Written Word. Boston, Rowman \& Littlefield Publishers, 1996, 277p.

DESIDERI, P. Scrivere gli eventi storici. IN Settis, S., Noi e I Greci, Torino, Einaudi, 1996, p.955-1013.

DOVER, K.J. Thucydides "as history” and "as literature". History 
and Theory, 22 (1983), p.54-63.

EDMUNDS, L. Chance and Intelligence in Thucydides. Cambridge, Harvard University Press, 1975, 243p.

ELLIS, J.R. The Structure and Argument of Thcydides' Archaeology, Classical Antiquity, 10 (1991), p.344-375.

GAISER, K. Das Staatsmodell des Thukydides. Zur Rede des Perikles für die Gefallenen. Heidelberg, F.H. Kerle Verlag, 1975, 112p.

HAMMOND, N.G.L. The Arrangement of Thought in the Proem and in other parts of Thucydides I, Classical Quarterly, 2 (1952), p. 127-141

HARTOG, F. L'oeil de Thcydide et l'histoire véritable. Poétique, 49 (1982), p.22-30.

HORNBLOWER, S. Thucydides. London, Duckworth, 1987, 230p. HORNBLOWER, S. A Commentary on Thucydides, v. I, Oxford, Clarendon Press, 1992, 548p.

HORNBLOWER, S. Narratology and Narrative Techniques in Thucydides, in Honrblower, S., Greek Historiography, Oxfor, Clarendon Press, 1994, p.131-166.

LORAUX, N. L'Invention d'Athènes. Paris, Mouton, 1981, 507p. LORAUX, N. Thucydide a écrit la Guerre du Peloponnèse. Metis, 1 (1984), p.139-161.
MURARI PIRES, F. Mito e História (Homero, Tucídides e os Princípios da Narrativa). Mimeo, São Paulo, FFLCH-USP, 1995, 230p.

NENCI, G. Il Motivo dell' autopsia nella Storiografia Greca. Studi Classici e Orientali, 3 (1955), p.14-46.

ORWIN, C. The Humanity of Thucydides. Princeton, Princeton University Press, 1994, 235p.

PARRY, A. M. Logos and Ergon in Thucydides. Salem, Ayer, 1988, 223p.

PLANT, I. A Note on Thucydides I.22.1. Athenaeum, 66 (1988), p.201-202.

PROCTOR, D. The Experience of Thucydides. Wraminster, Aris \& Phillips, 1980, 263p.

SCHEPENS, G. L'Autopsie dans la Méthode des Historiens Grecs du Vème siècle avant J.C., Brussel, 1980, 172p.

THUCYDIDE La Guerre du Péloponnèse. Livre II, texte établi et traduit par Jacqueline de Romilly, Paris, Les Belles Lettres, 1962, 106p.

WESTLAKE, H.D. Legetai in Thucydides. Mnemosyne, 30 (1977), p.345-362.

WOODMAN, A.J. Rhetoric in Classical Historiography. London, Croom Helm, 1988, 236p.

Endereço do Autor: Depto. de História, FFLCH/USP • Av. Prof. Lineu Prestes $338 \bullet$ Cidade Universitária $\bullet$ São Paulo • SP • Brasil • CEP 05508-900 • FAX (011) 818-3150 